\title{
Exploring Motivational Factors and Self-Regulated Learning Strategies as Predictors of Students' Anxiety in Mathematics Learning
}

\author{
Elias Kaphesi \\ University of Malawi-The Polytechnic, Blantyre, Malawi
}

\begin{abstract}
Learning is a complex process that involves interaction of factors which are too numerous to count. The purpose of this study is to determine whether motivational factors and self-regulated learning strategies are significant predictors of students' mathematics anxiety in secondary schools in Malawi. The subscales for the motivation investigated in this study were intrinsic goal orientation, extrinsic goal orientation, task value, control of learning beliefs, self-efficacy for learning, and anxiety. While the subscales for the self-regulated learning strategies scale are rehearsal, elaboration, organization, critical thinking, self-regulation, time and study environment management, effort regulation, peer-learning, and help-seeking. The study group was comprised of 184 secondary school students. It was found that students' motivational factors and self-regulated learning strategies were significant predictors of students' mathematics anxiety. The findings are useful to educators in the research areas of mathematics education. It is hopeful that the proposed model will become a useful reference for further investigations of factors influencing mathematics anxiety.
\end{abstract}

Keywords: education, mathematics, students' motivational factors, learning strategies, math anxiety

\section{Introduction}

Research indicates that there are many factors influencing self-regulated learning strategies (Pintrich, 2004; Shores \& Shannon, 2007; Garcia \& Pintrich, 1996). A review of literature on mathematics self-concept, mathematics self-efficacy, beliefs toward mathematics and affective toward mathematics has shown that these variables are closely related to mathematics self-regulated learning strategies (Zimmerman, 2003; 2002). However, the inter-relationships of these variables and their causal effects on each other are still unclear. Much recent research has focused on the various aspects of teaching and investigated how the motivational factors and self-regulated learning strategies influence students' achievement in mathematics (Wolters, 2003; Kurman, 2006). However, there are very few studies on students' predictors of learning behaviours, such as mathematics anxiety.

Self-regulated learning strategies, motivational factors, and anxiety are all interrelated and are likely to affect academic self-regulated learning strategies (Eccles \& Wigfield, 2002). It is argued that these factors form a complex network that brings about changes in mathematics self-regulated learning strategies (Pintrich, 2004; Garcia \& Pintrich, 1996). Therefore, the focus of this study is to clarify the directions and magnitude of the

Elias Kaphesi, Dr, senior lecturer, Mathematics and Statistics Department, University of Malawi-The Polytechnic. 
relationships between these variables among students of secondary mathematics. In doing so, a path model is created to explain the relationships between motivational factors, self-regulated learning strategies, and mathematics anxiety.

Motivational factors are more complex than the additive effects of student ability, perceived competence and self-regulated learning strategies desire, even though they significantly contribute to the students' desire to successfully participate in mathematical activities and to do well in mathematics. Kurman (2006), however, adopted a somehow different position. He argued that only when students perceive that self-regulated learning strategies will lead to rewards they value and, further, believe that their own hard work will result in self-regulated learning strategies will their engagement in mathematics learning increase.

The importance of motivational factors, self-regulated learning strategies, and mathematics anxiety in mathematics courses and the apparent differences between boys and girls' views has been demonstrated by Watt's (2011) argument that boys maintain higher intrinsic value for mathematics and higher mathematics related self-perceptions than girls throughout adolescence (Kurman, 2006). However, it is important to understand how it is that boys come to be more interested and like mathematics more than girls; and also why girls perceive themselves as having less talent, even when they perform similarly well (Pajares, 2002). Finding from the Program of International Student Assessment's (2003) study relating to girls' confidence in mathematics indicated that females appear to be less engaged, more anxious, and less confident in mathematics than males. Mathematical confidence, which is related to anxiety, is an affective dimension closely associated with mathematics self-regulated learning strategies.

Fear and anxiety are the cornerstones of low self-esteem in mathematics. Those who suffer from low self-esteem experience extreme fear and anxiety frequently. Believing that there is something innately wrong with themselves, these low self-esteem sufferers experience self-esteem attacks (often called panic attacks) when they do something they deem to have been stupid, something they think others have noticed, and something that confirms their own feelings of inadequacy, incompetence, being undeserving, or unlovable. During these attacks they may attack or withdraw and isolate while feeling embarrassed, humiliated, devastated, depressed, and even despairing. Depending on how seriously they perceive their "mistake" they may not recover for minutes, hours, days, or longer. They are often too fearful to ask for help, thinking that needing help is an admission of inadequacy. This state of mind often accounts for low achievement in mathematics.

\section{Aims of the Study}

The aim of this study is to determine whether motivational factors and self-regulated learning strategies are predictors of students' mathematics anxiety among secondary school students. In this respect, the following questions are answered in this study:

1. Are motivational factors significant predictors of students' mathematics anxiety?

2. Are self-regulated learning strategies significant predictors of college students' mathematics anxiety?

3. Is there any correlation between motivational factors and self-regulated learning strategies?

\section{Significance of the Study}

The motivational factors of students are of particular significance and importance because of their potential influence on their future beliefs and actions related to learning mathematics. Motivational factors contribute to students' performance in mathematics. It is highly undesirable for those who have unfavourable feelings about mathematics to employ appropriate strategies for learning mathematics in school. Furthermore, 
lack of motivation coupled with inappropriate learning strategies may lead to anxiety and frustration. Thus, it seems reasonable to assess the relationships among motivational factors, self-regulated strategies, and mathematics anxiety. Therefore, the study is practically significant to the curriculum designers to cater for the motivational factors, self-regulated strategies and reduced math anxiety among students by some interventions. It is also of policy significant, in long term, to set up appropriate selection criteria for admission to secondary schools and revise the curriculum of mathematics for secondary schools, so as to improve the quality of learning mathematics for students in secondary school.

Furthermore, the study is theoretically significant to find out to what extent the motivational factors influence their self-regulated learning strategies, and in turn, the effect on anxiety in mathematics. In particular, the model proposed is able to explain the interrelationship of motivational factors, self-regulated learning strategies and anxiety. The strength of the factors and the relations within and between the motivational factors, the self-regulated learning strategies and anxiety can also be found through stepwise linear regression analysis modeling. As a result, the findings of the study may form the basis for future intervention programmes which aim at improving students' motivation and self-regulated learning strategies in mathematics.

\section{Literature Review}

Understanding mathematics is a key for most career opportunities. Moreover, it is possible to make use of mathematics strategies in certain areas of science, like economics, politics, social studies, genetics, and medicine (Roman, 2004). Mathematics skills, used in many fields, are composed of computation skills and problem-solving skills (Schunk, 2000). There are some questions the students should ask themselves in order to gain these skills. The answers for these questions focus on the concepts of motivational factors (Eccles \& Wigfield, 2002; Linnenbrink \& Pintrich, 2002; Metallidou \& Vlachou, 2007; Pintrich, 2004), self-regulation (Zimmerman, 2002), and mathematics anxiety.

\section{Theoretical Framework for the Study}

The literature suggests that when students possess motivational factors and use self-regulated learning strategies for mathematics learning, their successes increase (Camahalan, 2006; Dresel, \& Haugwitz, 2005; Malmivuori, 2006; Metallidou \& Vlachou, 2007; Yukselturk \& Bulut, 2007). On the other hand, if they do not use these factors and strategies effectively, their failure and anxiety may increase (Kurman, 2006). Students must organize their motivational factors and self-regulated learning strategies to decrease their mathematics anxiety and become successful in mathematics. In other words, examining motivational factors and self-regulated learning strategies can serve as a clue for reasons of mathematics success or failure (mathematics anxiety). The proposed theoretical framework for analysing students' motivation is useful in investigating the relationship among motivational factors, learning strategies, and mathematics anxiety. The framework is useful in clarifying students' notion of what it might mean to be motivated to learn mathematics, what strategies learners use, and whether these two influence math anxiety. Figure 1 provides a summary of my understanding of how the three aspects of mathematics learning are linked together.

Bandura (1997) emphasized the importance of individuals' motivational processes and he further stated that individuals should shape their beliefs about their abilities, set negative and positive outcomes, and anticipate different pursuits and goals for themselves. He pointed out that self-efficacy and belief had a significant role in regulation of motivation in addition to these. On the other hand, Linnenbrink and Pintrich 
(2002) dwelt upon a different dimension of motivation and defined it as an academic enabler. They stated that self-efficacy, attributions, intrinsic motivation, and goals are significant for students' motivation. Pintrich (2004) emphasized the importance of motivational factors in the learning process and underlined the fact that motivational factors-goal orientation, self-efficacy, perceptions of task difficulty, task value beliefs, and personal interest in the task-should be regulated by the students to be effective in learning process.

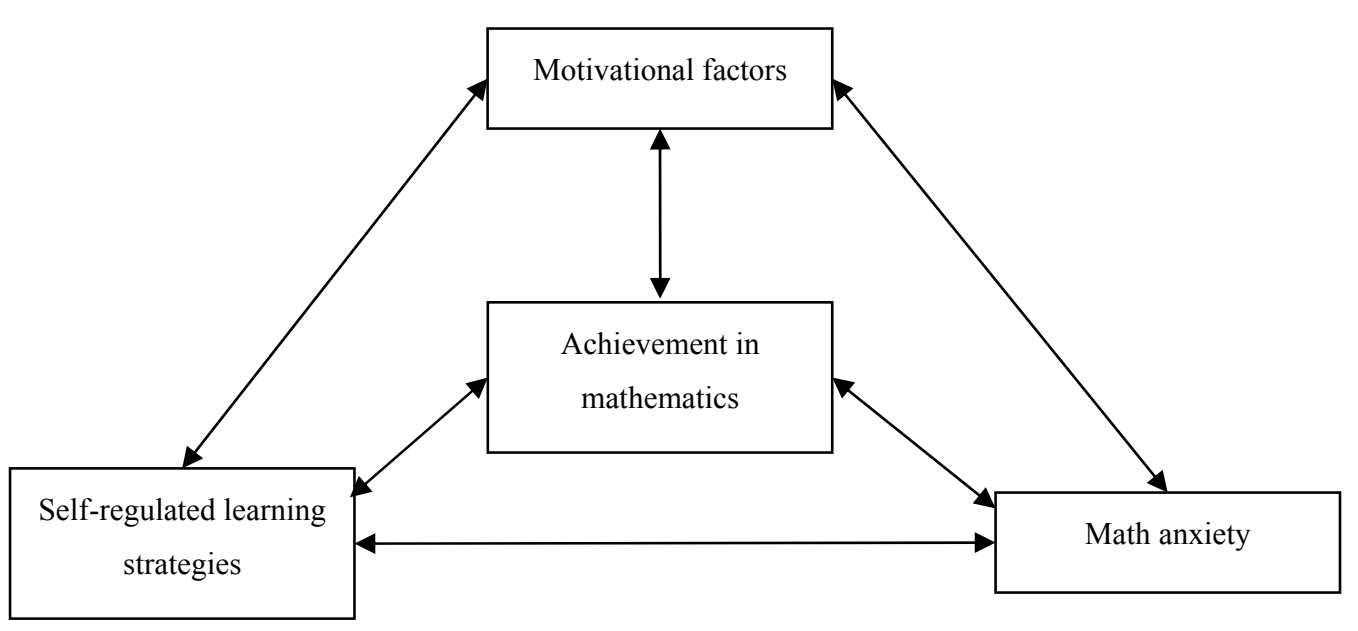

Figure 1. The relationship among motivational factors, learning strategies, and mathematics anxiety.

For students to become successful in mathematics, they should have not only motivational factors, but also employ appropriate self-regulated learning strategies. A learning strategy is a person's approach to learning and using information. Students use learning strategies to help them understand information and solve problems. Students who do not know or use good learning strategies often learn passively and ultimately fail in school. Learning strategy instruction focuses on making students more active learners by teaching them how to learn and how to use what they have learned to be successful.

\section{Levels of Self-Regulated Process}

Self-regulated learning materializes with both students' motivational factors and self-regulated learning strategies. Self-regulated learning requires a process, which, according to Schunk and Zimmerman (2002), had three major levels: self-observation, self-judgment, and self-reaction. In this process, planning, managing time, attending to and concentrating on instruction, using cognitive self-regulated learning strategies, building a productive study environment, and making use of social sources are crucial. In addition to these, strategies for evaluating motivational processes like setting performance goals and outcomes, holding a positive attitude about one's capabilities, and evaluating learning, its outcomes, and positive experiences that can affect learning have a considerable role. As Boekaerts and Corno (2005) pointed out, students can gain skills in the areas of decision-making, problem-solving, and resource management in education, assessing teaching, and completing the intervention required, depending on the assessment results, based on a certain process and program.

Students' success increases when these motivational factors are supported with self-regulated strategies. Eccles and Wigfield (2002) stated that such motivational factors as task value, expectancies, and values were important for student success in mathematics. As Pintrich (2004) stated, this importance was based on general assumptions of the self-regulated learning, such as active, constructive, and potential for control assumption, 
goal and criterion for learning. As Wolters (2003) pointed out, in models of self-regulated learning, students became more effective when they took a purposeful task. Furthermore, students' motivational factors and self-regulated learning strategies contributed most to the students to carry out any learning task.

Cleary and Zimmerman (2004) made it clear that highly self-regulated learner's approach learning tasks with self-confidence (reduced anxiety), proactively set goals, and developed a plan to realize their own learning and reached their learning goals. Whether self-regulated learners are aware of the ability they have or not is a predictor of their success or failure. Self-regulated learners search information themselves and they do the necessities to improve the information they have reached. Zimmerman and Campillio (2003) stated learners should have the characteristics of self-generated thoughts (self-confidence), feelings (motivational factors), and actions (strategies) cyclically planned to reach their personal targets. At the same time, these characteristics should be backed up with cognitive and metacognitive strategies and effort. This support, as Pintrich (2000) stated, was achieved with the self-determined and active process of planning, executing, monitoring, and controlling of strategic learning.

Mathematics anxiety is a stress and anxiety situation related to students' negative experiences with mathematical concepts and procedures. Although many studies have shown that mathematics anxiety is related to such variables like age, sex, self-efficacy, and mathematics attitudes (Cates \& Rhymer, 2003), Oberlin (1982) indicated that teaching techniques led to mathematics anxiety. Jackson and Leffingwell (1999) noted that mathematics anxiety can occur if students have negative experiences at elementary and secondary schools, and they stated that having a hostile or intensive attitude towards the students, treating students prejudicially because of their gender, demonstrating an uncaring attitude, expressing anger, having unrealistic expectations, embarrassing students in front of peers, communication and language barriers, quality of instruction, evaluation methods, and difficulty of material were among the behaviors and attitudes of mathematics teachers that can cause mathematics anxiety. Likewise, Furner and Duffy (2002) indicated that the school system, gender, socioeconomic status, and parental background might affect mathematics anxiety, too. However, little is known whether what drive students hold towards learning mathematics (motivation) and what they do when learning mathematics (learning strategies) are a reflection of their mathematics anxiety. He/She perceives that the theoretical framework as an analytical tool captured the complexity and the richness of the students' motivation in detail, and the tool made it possible for his/her to present detailed descriptions of the students' motivation for learning mathematics.

\section{Research Methods}

In this study, a quantitative method was used. The quantitative data helped determine whether significant associations exist between independent variables and dependent variables. Motivational factors and self-regulated learning strategies were independent variables for the study, while mathematics anxiety was the dependent variable. In this study, the extent to which motivational factors and self-regulated learning strategies served as predictors of mathematics anxiety was analyzed.

\section{Participants}

Participants of this study were 184 students taking a general mathematics course in selected secondary schools in Malawi. The study group was formed from form three students. The group consisted of 184 students -93 (50.5\%) girls and 91 (49.5\%) boys. The schools were conveniently sampled, because our student 
teachers were conducting their teaching practices in these schools. Form three classes were purposively selected because these were non-examination classes who had stayed in secondary school long enough to provide appropriate information from experience

\section{Research Instrument}

A questionnaire was used to collect data for this study. The questionnaire contained the sections on personal background and motivational factors and possible self-regulated learning strategies (Dunn, Lo, Mulvenon, \& Sutcliffe, 2012). The self-regulated learning strategies in mathematics adapted from the Study Process Questionnaire (SPQ) developed by Biggs (1992) was used to measure the self-regulated learning strategies of students in this study (Hendricks, Ekici, \& Bulut, 2000; Karadeniz, Büyüköztürk, Akgün, K1liç-Çakmak, \& Demirel, 2008). This instrument consisted of 64 items on a five-point scale. In the questionnaire, the latent variable was measured through observed indicators in terms of items in the questionnaire. The questionnaire was designed using Likert scale responses on five-point continuum from "1" (Definitely false) to "5" (Definitely true). The ordered categories are simply scored with successive integers and a students' response is taken as the sum of the scores of all statements of the instruments. The reliability estimates of affective towards learning mathematics were reliable as the reported coefficient alpha was 0.92 (Duncan \& McKeachie, 2005).

\section{Data Collection Procedure}

The quantitative data were obtained from a survey questionnaire administered to 184 respondents. The sample consisted of form three students in five secondary schools in Malawi. The questionnaires were self-administered; the researcher collected the questionnaires immediately they were completed. In this way, the participants completed the questionnaires without consulting each other and $100 \%$ of the questionnaires were collected.

\section{Data Analysis}

Statistic Package for Social Science (SPSS) for Windows 16.0 was used to produce the frequencies and percentages for the scales of constructs and mathematics self-regulated learning strategies. After performing descriptive statistical analysis, reliability analysis was carried out for all the scales of the instruments. The reliability was measured by the internal consistency coefficient and assessed by calculating the coefficient alpha.

Next, the questionnaire items were initially subjected to a spearman correlation coefficient analysis. Given that the structure could vary, two factor analyses of the possible correlation between the motivational factors and self-regulated learning strategies were performed in order to investigate possible correlation between the two sets of factors. Finally, stepwise linear regression analysis was used. In stepwise linear regression analysis, the relationship between the predictor variables, students' motivational factors, and learning strategies, and the dependent variable, math anxiety, were tested. Data were analyzed by using SPSS 16.0 software.

\section{Results}

\section{Demographic Information}

The sample consisted of 184 form three students drawn from five government secondary schools. There were 93 (50.5\%) girls and 91 (49.5\%) boys. The gender representation was fairly equal in this study. All the schools were coeducation except one, which was girls, only school run by Catholic Church. Table 1 shows the 
age distribution of the students involved in this study. The majority of participants were of the ages between 14 and 18 with very few of ages 13,20 , and 25 years.

Table 1

Age Distribution of the Sample

\begin{tabular}{lcc}
\hline Ages (Years) & Frequency & Percentages (\%) \\
\hline 13 & 4 & 2.2 \\
14 & 21 & 11.4 \\
15 & 36 & 19.6 \\
16 & 54 & 29.3 \\
17 & 37 & 20.1 \\
18 & 24 & 13.0 \\
19 & 6 & 3.3 \\
20 & 1 & 0.5 \\
25 & 1 & 0.5 \\
\hline
\end{tabular}

The frequency distribution of the students responses regarding their self-regulated learning strategies towards mathematics learning is presented in Table 1 (Scores of " $4=$ Agree" and " $5=$ Strongly agree" have been combined as agree whereas the scores of " $1=$ Strongly agree" and " $2=$ Disagree as disagree." Scores for not sure formed the third category).

Table 2

The Average Percentages of Frequencies Students' Ratings of the Motivational Factors

\begin{tabular}{llll}
\hline \multirow{2}{*}{ Motivational factors } & \multicolumn{3}{c}{ Agreement } \\
\cline { 2 - 4 } & $M$ & $F$ & All \\
\hline Valuing math & 90.25 & 79.75 & 75.51 \\
Willingness to do math & 76.25 & 74.25 & 71.24 \\
Diligence & 74.43 & 69.29 & 63.05 \\
Enjoyment & 66.50 & 60.67 & 55.54 \\
Confidences & 64.00 & 44.67 & 47.49 \\
Reward for effort & 61.00 & 48.00 & 47.43 \\
Interest & 52.20 & 43.80 & 45.51 \\
Intellectual inspiration & 44.33 & 48.00 & 40.79 \\
Self-regulated learning strategies & 42.60 & 38.00 & 20.53 \\
Mathematics anxiety & 20.80 & 20.00 & \\
\hline
\end{tabular}

The average percentages of frequencies students' ratings of the motivational factors are presented in Table 2 for easy comparison. When motivational factors are compared, students seem to be very assertive about value of learning mathematics, willingness to do mathematics, diligence, enjoyment and talent, confidence and self-efficacy in learning mathematics. However, they seem not seeing much reward for their effort in learning mathematics. They are also less interested with weak intellectual stimulation. They are not sure about their approaches to mathematics learning but disagree that mathematics learning causes anxiety among students.

Table 3 shows that the majority of the students employ communication strategies in learning mathematics. At the bottom of the list is use of time and study environment to enhance concentration during mathematics learning. This implied that discussing and talking about mathematics is more valuable than silently organizing and working out mathematics problems. 
Table 3

Students' Mathematics Self-Regulated Learning Strategies

\begin{tabular}{llll}
\hline \multirow{2}{*}{ Students self-regulated learning strategies } & \multicolumn{2}{c}{ Agreement } \\
\cline { 2 - 4 } & $M$ & $F$ & All \\
\hline Communication behavior & 75.00 & 70.33 & 71.02 \\
Self-regulation & 74.73 & 68.99 & 70.65 \\
Critical thinking & 74.19 & 67.03 & 65.22 \\
Rehearsal & 70.43 & 59.89 & 65.49 \\
Exploratory behavior & 69.36 & 60.44 & 76.46 \\
Elaboration & 69.23 & 61.36 & 67.44 \\
Peer-learning & 69.18 & 65.75 & 64.68 \\
Help-seeking & 67.18 & 62.09 & 60.51 \\
Organization & 66.49 & 54.40 & 69.46 \\
Effort management & 65.38 & 73.63 & 67.75 \\
Time and study environment & 62.10 & 59.89 & \\
\hline
\end{tabular}

The results in Table 4 show that self-efficacy, math anxiety, and math enjoyment are all significantly correlated to all self-regulated learning strategies in mathematics whereas the rest of the motivational factors are correlated significantly to at least six self-regulated learning strategies at 0.01 level of significance. All self-regulated learning strategies are positively correlated to motivational factors except critical thinking which is negatively correlated to interest, intellectual stimulation and approaches to mathematics learning.

Table 4

Correlation Analysis

\begin{tabular}{|c|c|c|c|c|c|c|c|c|c|c|}
\hline & 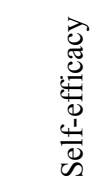 & 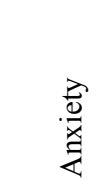 & 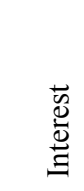 & 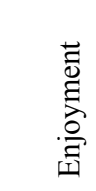 & 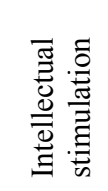 & 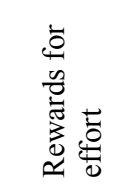 & 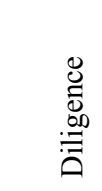 & 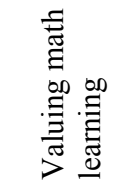 & 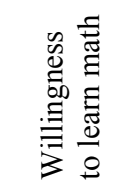 & 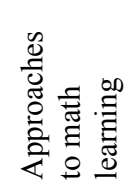 \\
\hline Rehearsal & 0.24 & 0.48 & 0.41 & 0.39 & 0.49 & 0.31 & 0.73 & 0.52 & 0.49 & 0.69 \\
\hline Elaboration & 0.61 & 0.28 & 0.22 & 0.32 & 0.28 & 0.13 & 0.16 & 0.32 & 0.09 & 0.16 \\
\hline Organization & 0.89 & 0.37 & 0.27 & 0.29 & 0.28 & 0.14 & 0.25 & 0.24 & 0.40 & 0.40 \\
\hline Critical thinking & 0.52 & 0.26 & -0.03 & 0.38 & -0.02 & 0.08 & 0.02 & 0.24 & 0.03 & -0.01 \\
\hline Self-regulation & 0.53 & 0.23 & 0.11 & 0.29 & 0.29 & 0.25 & 0.16 & 0.32 & 0.23 & 0.22 \\
\hline Effort management & 0.34 & 0.25 & 0.01 & 0.30 & 0.21 & 0.15 & 0.19 & 0.31 & 0.15 & 0.18 \\
\hline Study environment & 0.62 & 0.34 & 0.25 & 0.33 & 0.42 & 0.28 & 0.35 & 0.44 & 0.39 & 0.43 \\
\hline Peer learning & 0.54 & 0.36 & 0.20 & 0.22 & 0.23 & 0.22 & 0.28 & 0.29 & 0.35 & 0.43 \\
\hline Help seeking & 0.44 & 0.47 & 0.23 & 0.33 & 0.36 & 0.24 & 0.42 & 0.44 & 0.43 & 0.47 \\
\hline Exploratory behaviour & 0.39 & 0.27 & 0.13 & 0.28 & 0.31 & 0.15 & 0.32 & 0.28 & 0.23 & 0.24 \\
\hline Communication behaviou & 0.40 & 0.32 & 0.20 & 0.44 & 0.18 & 0.22 & 0.20 & 0.50 & 0.32 & 0.28 \\
\hline
\end{tabular}

Participants in this study were asked to rate their opinions on mathematics anxiety items and their responses are summarized in Table 5. The results show that the majority of students experienced anxiety when the thought of the consequences of failing mathematics. This makes them remember most tasks that they failed to answer previously. The fears are likely result of personal experience about mathematics learning. However, students become less nervous and continue to fight. 


\section{Stepwise Linear Regression Analysis Models}

Three stepwise linear regression analyses were conducted. First, a stepwise regression analysis method was used to determine whether affective factors are predictors of students' mathematics motivational factors. Findings from stepwise regression analysis are summarized in Table 6. It appears from the results that there is a very weak relationship $(r=0.077)$ between motivational factors and mathematics anxiety. According to the findings of the study (see Table 6), motivational factors are not significant predictors of students' mathematics anxiety $(p<0.05)$. About $7.7 \%$ of the variance in mathematics anxiety was explained by motivational factors.

Table 5

Mathematics Anxiety

\begin{tabular}{lcc}
\hline Mathematics anxiety: when taking exams & $N$ & Percentages (\%) \\
\hline I always think about the consequence of failing. & 118 & 63.0 \\
I keep thinking of the questions that I failed to answer in previous exams. & 104 & 56.6 \\
I feel nervous and worry. & 67 & 36.4 \\
My heart beat faster. & 57 & 31.0 \\
Before taking math exam, I am too wary to take a good sleep. & 48 & 26.1 \\
I feel inferior to other classmates. & 47 & 20.2 \\
I am totally blank and can not remember what I learned before. & 33 & 17.9
\end{tabular}

Table 6

Summary of Stepwise Regression Analysis Between Motivational Factors and Mathematics Anxiety.

\begin{tabular}{|c|c|c|c|c|c|c|}
\hline \multirow{2}{*}{ Model } & & \multicolumn{2}{|c|}{ Unstandardized coefficients } & \multirow{2}{*}{$\begin{array}{l}\text { Standardized coefficients } \\
B\end{array}$} & & \multirow{2}{*}{ Sig. } \\
\hline & & $B$ & Std. error & & & \\
\hline \multirow{2}{*}{1} & (Constant) & 3.654 & 0.375 & \multirow{2}{*}{0.077} & 9.739 & 0.000 \\
\hline & Affective factors & 0.085 & 0.096 & & 0.892 & 0.374 \\
\hline
\end{tabular}

Second, a stepwise regression analysis method was used to determine whether motivational factors are predictors of students' mathematics anxiety. Findings from stepwise regression analysis are summarized in Table 7. It appears from the results that there is a very weak relationship $(r=0.057)$ between motivational factors and mathematics anxiety. According to the findings of the study (see Table 7), motivational factors are not significant predictors of students' mathematics anxiety $(p<0.05)$. About $5.7 \%$ of the variance in mathematics anxiety was explained by motivational factors.

Table 7

Summary of Stepwise Regression Analysis Between Motivational Factors and Mathematics Anxiety

\begin{tabular}{lllllll}
\hline \multirow{2}{*}{ Model } & & \multicolumn{2}{c}{ Unstandardized coefficients } & \multicolumn{2}{c}{ Standardized coefficients } & \multicolumn{2}{c}{ Sig. } \\
\cline { 3 - 7 } & & $B$ & Std. error & $B$ & 9.056 & 0.000 \\
\hline \multirow{2}{*}{1} & (Constant) & 3.408 & 0.376 & 0.057 & 0.656 & 0.513 \\
\hline
\end{tabular}

Second, the stepwise regression analysis method was used to determine whether affective factors are predictors of students' mathematics anxiety. Findings from stepwise regression analysis are summarized in Table 8. 
Table 8

Summary of Stepwise Regression Analysis Between Affective and Motivational Factors

\begin{tabular}{|c|c|c|c|c|c|c|}
\hline \multirow{2}{*}{ Model } & & \multicolumn{2}{|c|}{ Unstandardized coefficients } & \multirow{2}{*}{$\begin{array}{l}\text { Standardized coefficients } \\
B\end{array}$} & & \multirow{2}{*}{ Sig. } \\
\hline & & $B$ & Std. error & & & \\
\hline \multirow{2}{*}{1} & (Constant) & 0.798 & 0.319 & \multirow{2}{*}{0.617} & 2.500 & 0.014 \\
\hline & Affective factors & 0.735 & 0.081 & & 9.042 & 0.000 \\
\hline
\end{tabular}

Third, the model derived from the analysis of the data is " $y=0.74 x+0.80$." Considering that $r=0.617$, there is a strong relationship between affective factors and mathematics anxiety. According to these results, affective factors were found to be significant predictors of students' mathematics anxiety $(p<0.01)$. About $62 \%(61.7 \%)$ of the variance in mathematics anxiety was explained by affective factors.

The stepwise regression analysis method was used to determine whether self-regulated learning strategies are predictors of students' mathematics anxiety. Findings from stepwise regression analysis are summarized in Table 9 .

Table 9

Summary of Stepwise Regression Analysis Between Learning Strategies and Mathematics Anxiety

\begin{tabular}{lllllr}
\hline \multirow{2}{*}{ Model } & & \multicolumn{2}{c}{ Unstandardized coefficients } & \multicolumn{2}{c}{ Standardized coefficients } \\
\cline { 3 - 5 } & & $B$ & Std. error & $B$ & Sig. \\
\hline \multirow{2}{*}{1} & (Constant) & 2.134 & 0.360 & 0.347 & 5.933 \\
& Learning strategies & 0.452 & 0.106 & 0.000 & 4.273 \\
\hline
\end{tabular}

According to these results, the relationship between learning strategies and mathematics anxiety is weak ( $r$ $=0.347$ ). A model derived from the analysis of the data is " $y=0.45 x+0.213$." This shows that learning strategies were found to be significant predictors of students' mathematics anxiety $(p<0.01)$. About $35 \%$ $(34.7 \%)$ of the variance in mathematics anxiety was explained by learning strategies.

\section{Discussion}

Based on the findings of this study, motivational factors are not significant predictors for mathematics anxiety. The strong negative correlations between mathematics anxiety and motivational factors in mathematics provide considerable support for the findings of this study (Ashcraft, 2002). The findings support the views that mathematics anxiety is a subscale of motivational factors though in the negative.

Almost all self-regulated learning strategies are positively correlated to motivational factors except critical thinking which is negatively correlated to interest, intellectual stimulation, and approaches to mathematics learning. Students' motivational factors should be increased and they should gain self-regulated learning strategies for being successful in mathematics or coping with mathematics anxiety. In a study in which the correlations between the goal orientations of the students, motivational factors, and self-regulated learning, adopting a learning goal orientation, and a relative ability are examined, goal orientation results in a generally positive pattern of motivational factors, including adaptive levels of task value, self-efficacy, and anxiety, as well as cognition, including higher levels of cognitive strategy use, self-regulation, and academic performance (Shores \& Shannon, 2007; Wolters \& Yu, 1996). To become successful, students should determine their individual beliefs about how well they will do in upcoming tasks, specific, proximal, divergent goals, values, motivational factors, and learning strategies, such as cognitive and metacognitive strategies, and they should 
behave in a planned way, according to these factors and strategies (Eccles \& Wigfield, 2002).

Besides having high motivational factors, students should be aware of their self-regulated learning strategies and they should use these strategies effectively in mathematics to cope with mathematics anxiety. Most important, students should take responsibility for their learning. Related with the awareness of self-regulated learning, Zimmerman (2002) stated that self-regulated learners were aware of regulating the learning process, learning responses, and learning outcomes, and they used these strategies to reach their academic goals. In addition to self-regulated learning strategies, other strategies like self-evaluation, organization, transformation, goal setting and planning, information seeking, record keeping, self-monitoring, environmental structuring, giving self-consequence, rehearsing and memorizing, seeking social assistance, and reviewing should be used (Zimmerman, 2002). For effectiveness of self-regulated learning, individuals should engage in self-monitoring in order to ignore the obstacles in using cognitive learning strategies and the conflicts that occur while gaining a learning objective (Zimmerman, 2002).

\section{Conclusion}

In conclusion, motivational factors and self-regulated learning strategies influence each other as well influence cognitive activities in the learning process and subsequently mathematics anxiety. Stepwise linear regression analysis model starts from a conceptually derived model specifying the relationships among a set of variables. Theory based on the literature and pilot studies provides the centrepiece for structural equation methodologies designed for use with substantive interests in understanding complex patterns of interrelationships among variables. Cause and effect in the structural equation model are totally dependent on the way in which the relationships are specified and the results at best indicate to plausibility about the relationships. However, the strength and conviction with which the researcher can assume causation between two variables lies not in the analytical methods chosen but in the theoretical justification provided to support the analysis. The result also shows that affective factors and learning strategies act as the mediator of mathematics anxiety. The finding proves useful to educators in the research areas of affective domain of mathematics.

\section{References}

Ashcraft, M. H. (2002). Math anxiety: Personal, educational, and cognitive consequences. Current Directions in Psychological Science, 77(5), 181-185.

Bandura, A. (1997). Self-efficacy: The exercise of control. New York, N. Y.: W. H. Freeman.

Boekaerts, M., \& Corno, L. (2005). Self-regulation in the classroom: A perspective on assessment and intervention. Applied Psychology: An International Review, 54(2), 199-231.

Camahalan, F. M. (2006). Effects of self-regulated learning on mathematics achievement of selected Southeast Asian children. Journal of Instructional Psychology, 33(3), 194-205.

Cates, G. L., \& Rhymer, K. N. (2003). Examining the relationship between math anxiety and mathematics performance: An instructional hierarchy perspective. Journal of Behavioral Education, 72(1), 23-34.

Cleary, T. J., \& Zimmerman, B. J. (2004). Self-regulation empowerment program: A school-based program to enhance self-regulated and self-motivated cycles of student learning. Psychology in the Schools, 41(5), 537-550.

Dresel, M., \& Haugwitz, M. (2005). The relationship between cognitive abilities and self-regulated learning: Evidence for interactions with academic self-concept and gender. High Ability Studies, 16(2), 201-218.

Duncan, T. G., \& McKeachie, W. J. (2005). The making of the motivated strategies for learning questionnaire. Educational Psychologist, 40, 117-128.

Dunn, K. E., Lo, W. J., Mulvenon, S. W., \& Sutcliffe, R. (2012). Revisiting the motivated strategies for learning questionnaire: A theoretical and statistical reevaluation of the metacognitive self-regulation and effort regulation subscales. Educational and Psychological Measurement, 72(2), 312-331. 
Eccles, J. S., \& Wigfield, A. (2002). Motivational beliefs, values, and goals. Annual Review of Psychology, 53(1), $109-132$.

Garcia, T., \& Pintrich, P. R. (1996). Assessing students' motivation and learning strategies in the classroom context: The motivated strategies for learning questionnaire. Alternatives in Assessment of Achievements, Learning Processes and Prior Knowledge Evaluation in Education and Human Services, 42, 319-339.

Hendricks, N. J., Ekici, C., \& Bulut, S. (2000). Adaptation of motivated strategies for learning questionnaire (Unpublished research report, Middle East Technical University, Ankara, Turkey).

Karadeniz, Ş., Büyüköztürk, Ş., Akgün, Ö. E., Kılıç-Çakmak, E., \& Demirel, F. (2008). The Turkish adaptation study of Motivated Strategies for Learning Questionnaire (MSLQ) for 12-18 year old children: Results of confirmatory factor analysis. The Turkish Online Journal of Educational Technology, 7(4), Article 12.

Kurman, J. (2006). Self-enhancement, self-regulation, and self-improvement following failures. British Journal of Social Psychology, 45, 339-356.

Linnenbrink, E. A., \& Pintrich, P. R. (2002). Motivation as an enabler for academic success. School Psychology Review, 31(3), 313-327.

Malmivuori, M. (2006). Affect and self-regulation. Educational Studies in Mathematics, 63, 149-164.

Metallidou, P., \& Vlachou, A. (2007). Motivational beliefs, cognitive engagement, and achievement in language and mathematics in elementary school children. International Journal of Psychology, 42(1), 2-15.

Pajares, F. (2002). Gender and perceived self-efficacy in self-regulated learning. Theory Into Practice, 41(2), 116-125.

Pintrich, P. R. (2004). A conceptual framework for assessing motivation and self-regulated learning in college students. Educational Psychology Review, 16(4), 385-407.

Roman, H. T. (2004). Why math is so important. Tech Directions, 63(10), 16-18.

Shores, M. L., \& Shannon, D. M. (2007). The Effects of self-regulation, motivation, anxiety, and attributions on mathematics achievement for fifth and sixth grade students. School Science and Mathematics, 107(6), 225-236.

Schunk, D. H. (2000). Learning theories: An educational perspective. NewJersey: Merrill Prentice Hall.

Watts, B. K. (2011). Relationships of mathematics anxiety, mathematics self-efficacy and mathematics performance of adult basic education students (Doctoral dissertation, Capella University).

Wolters, C. A. (2003). Regulation of motivation: Evaluating an underemphasized aspect of self-regulated learning. Educational Psychologist, 38(4), 189-205.

Zimmerman, B. J., \& Campillio, M. (2003). Motivating self-regulated problem solvers. In J. E. Davidson \& R. J. Sternberg (Eds.), The psychology of problem solving (pp. 233-262). Cambridge, U.K.: Cambridge University Press.

Zimmerman, B. J. (2002). Becoming a self-regulated learner: An overview. Theory Into Practice, 41(2), 64-70. 